\title{
Insulin-dependent inhibition of hepatic glycogenolysis by gastric inhibitory polypeptide (GIP) in perfused rat liver
}

\author{
H. Hartmann, R. Ebert and W. Creutzfeldt \\ Division of Gastroenterology and Metabolism, Department of Medicine, University of Göttingen, Federal Republic of Germany
}

\begin{abstract}
Summary. The effect of porcine gastric inhibitory polypeptide on hepatic glycogen metabolism was investigated in the isolated in situ perfused rat liver. Glycogenolysis was stimulated by infusion of glucagon into the portal vein (half maximal effective portal vein concentration $\sim 30 \mathrm{pmol} / \mathrm{l}$ ). When glucagon was infused at a final portal vein concentration of $0.5 \mathrm{nmol} / \mathrm{l}$, simultaneous addition of insulin inhibited the glucagon-dependent glycogenolysis in a dose-dependent way (half maximal effective concentration for insulin about $2 \mathrm{nmol} / \mathrm{l}$ ). Gastric inhibitory polypeptide alone at a concentration of $1 \mathrm{nmol} / 1$ reduced glucagon-dependent glycogenolysis only
\end{abstract}

slightly. However, when infused simultaneously at low insulin concentrations $(0.1 \mathrm{nmol} / 1)$, gastric inhibitory polypeptide suppressed hepatic glucose production dose-dependently up to $70 \%$. The data suggest that gastric inhibitory polypeptide exerts direct metabolic effects on hepatic glycogen metabolism predominantly in a situation where insulin is simultaneously present, e.g. following ingestion of glucose.

Key words: hepatic glycogenolysis, gastric inhibitory polypeptide (GIP), insulin, glucagon.
The role of gastric inhibitory polypeptide (GIP) - a gastrointestinal hormone released upon oral ingestion of glucose and fat - in modulating pancreatic insulin secretion has been well established [1, 2]. GIP is regarded as a component of the entero-insular axis [3].

Direct metabolic effects of GIP have not been demonstrated conclusively. Previous work in isolated rat fat cells has suggested a competitive antagonism towards the lipolytic action of glucagon [4], apparently mediated by decreased intracellular cyclic AMP levels [5]. In addition, GIP has been shown to stimulate lipoprotein lipase activity in cultured preadipocytes [6] and to increase uptake of triglycerides during infusion of chylomicrons in dogs [7].

The data on direct effects of GIP on liver carbohydrate metabolism are contradictory. It has been claimed that GIP exerts glucagon-like effects on hepatic glucose metabolism by increasing glucose production in the perfused rat liver [8]. On the other hand, insulin-dependent suppression of glucagon-induced glucose output by GIP has also been found using the isolated perfused rat liver [9]. Similarly, it has been demonstrated that GIP suppressed glucagon-dependent hepatic glucose production in the presence of insulin using the euglycaemic clamp technique in conscious dogs [10]. The aim of the present work was to study direct metabolic effects of GIP on hepatic glycogen metabolism in vitro using the perfused rat liver.

\section{Materials and methods}

\section{Materials}

Chemicals were reagent grade and from commercial sources. Enzymes were purchased from Boehringer Mannheim GmbH, Mannheim, FRG; bovine serum albumin, bovine glucagon and bovine insu- lin from Serva, Heidelberg, FRG. Porcine GIP was obtained from J.C. Brown, Vancouver, Canada.

\section{Animals}

Male Wistar rats (150-200 g) were kept on a $12 \mathrm{~h}$ day/night rhythm (dark period from $20.00 \mathrm{~h}$ to $08.00 \mathrm{~h}$ ) with free access to standard Altromin $^{\circledR}$ diet, Altromin, Lage, FRG.

\section{Liver perfusion}

All experiments were started at $09.30 \mathrm{~h}$ when the animals were just at the beginning of the postabsorptive phase with an average hepatic glycogen content of $400 \mu \mathrm{mol}$ glycosyl units $/ \mathrm{g}$ liver ${ }^{-1}$ [11]. After anaesthesia by intraperitoneal injection of pentobarbital $(60 \mathrm{mg} \times \mathrm{kg}$ body weight ${ }^{-1}$ ) the experiments were performed in a $37^{\circ} \mathrm{C}$ perfusion chamber (Krannich, Göttingen, FRG). Livers were perfused via the

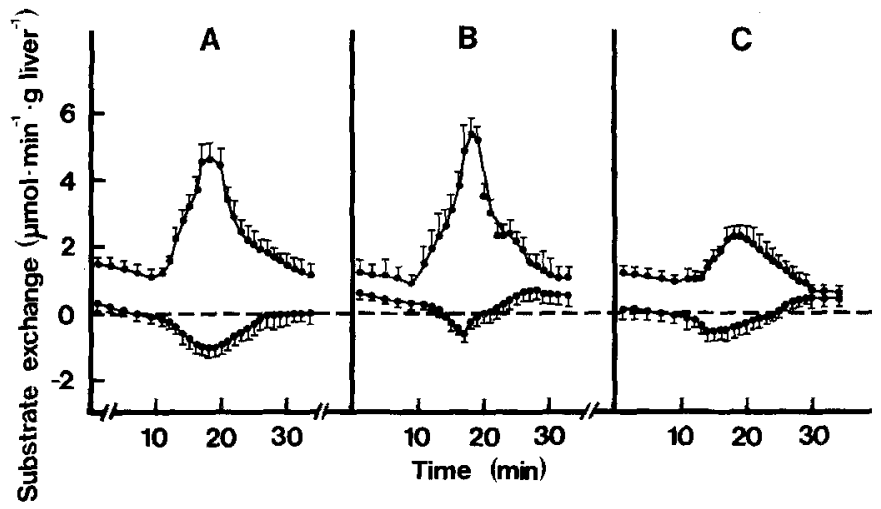

Fig. 1A-C. Suppression of glucagon-dependent stimulation of glycogenolysis in the in situ perfused rat liver by gastric inhibitory polypeptide (GIP) in the presence of insulin. In $A$ only glucagon $(0.5 \mathrm{nmol} / 1)$, in B glucagon and insulin $(0.1 \mathrm{nmol} / \mathrm{l})$, in $\mathrm{C}$ glucagon, insulin and GIP (1 nmol/l) were infused simultaneously into the portal vein. The bars indicate infusion periods of $5 \mathrm{~min}(11-15 \mathrm{~min})$. The upper curves depict glucose, the lower curves lactate exchange. Values are means \pm SEM of 6 experiments for $A$ and of 5 and 4 experiments for $\mathbf{B}$ and $\mathbf{C}$ respectively 


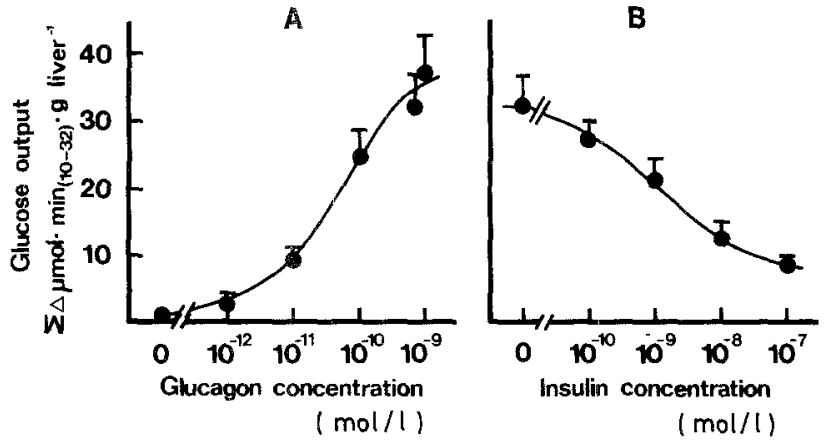

Fig. 2 A and B. Dose response curves for A stimulative action of glucagon on hepatic glycogenolysis and $\mathbf{B}$ suppressive action of insulin on glucagon $(0.5 \mathrm{nmol} / 1)$-dependent glycogenolysis. Livers were perfused as depicted in Fig. 1. Glucose output was calculated by integrating the area under the curve for glucose output from the beginning of hormone infusion to $\min 32$ and subtracting the preinfusion values. In A various concentrations of glucagon, in $\mathbf{B}$ simultaneous infusion of a fixed concentration of glucagon $(0.5 \mathrm{nmol} / \mathrm{l})$ and various concentrations of insulin were infused. Values are means \pm SEM for $\mathbf{A}$ of 3 $\left(10^{-12}, 10^{-11}, 10^{-9}\right), 4\left(10^{-10}\right)$ experiments, for $\mathbf{B}$ of $4\left(10^{-7}, 10^{-8}\right.$, $\left.10^{-9}\right), 5\left(10^{-10}\right)$ and $6(0)$ experiments

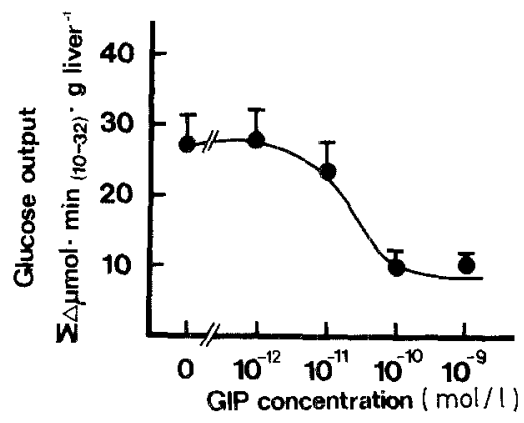

Fig. 3. Dose response curve for the suppressive action of GIP on glucagon $(0.5 \mathrm{nmol} / 1)$-dependent glycogenolysis in the presence of insulin $(0.1 \mathrm{nmol} / 1)$. Hormones were infused as indicated in Fig. 1, glucose output calculated as described in Fig. 2. Values are means \pm SEM of 3 $\left(10^{-10}, 10^{-12}\right), 4\left(10^{-9}, 10^{-11}\right)$ and $5(0)$ experiments

portal vein without recirculation and hepatic venous samples were collected every minute as described previously [12]. Substrate balances across the liver, e.g. glucose output and lactate uptake, were calculated by substracting the portal input from the hepatic output (given by portal and hepatic vein substrate concentrations and flow of the medium).

Perfusion media consisted of $30 \%(\mathrm{v} / \mathrm{v})$ washed bovine red cells suspended in Krebs-Ringer bicarbonate buffer containing 2\% (w/v) of bovine serum albumin. Medium glucose and lactate concentrations were adjusted to $5 \mathrm{mmol} / 1$ and $2 \mathrm{mmol} / 1$ respectively. The flow rate was kept at a rate of 1.8 to $2.0 \mathrm{ml} \cdot \mathrm{min}^{-1} \cdot \mathrm{g} \mathrm{liver}^{-1}$, thus resembling physiological flow rates [13, 14]. After an equilibration period of $45 \mathrm{~min}$, samples were collected and hormones were infused into the portal vein for the indicated time periods. Glucose and lactate concentrations were measured photometrically with enzymatic methods using hexokinase plus glucose-6-phosphate dehydrogenase and lactate dehydrogenase [15].

\section{Results}

\section{Stimulation of glycogenolysis by glucagon}

When glucagon $(0.5 \mathrm{nmol} / 1)$ was infused into the portal vein, an increase of hepatic glucose output and an in-
Table 1. Effect of gastric inhibitory polypeptide (GIP) on glycogenolysis in the perfused rat liver

\begin{tabular}{|c|c|c|}
\hline \multicolumn{2}{|c|}{$\begin{array}{l}\text { Condition } \\
\text { Hormone concentration }\end{array}$} & \multirow[t]{2}{*}{$\begin{array}{l}\text { Change in glucose output } \\
{\left[\Sigma \Delta \mu \mathrm{mol} \cdot \min _{(10-32)} \cdot \mathrm{g} \mathrm{liver}^{-1}\right]}\end{array}$} \\
\hline & $\mathrm{nmol} / 1$ & \\
\hline 1. GIP & 1.0 & $4.9 \pm 0.4$ \\
\hline 2. Glucagon & 0.5 & $31.5 \pm 5.3$ \\
\hline $\begin{array}{l}\text { 3. Glucagon } \\
\text { Insulin }\end{array}$ & $\begin{array}{l}0.5 \\
0.1\end{array}$ & $26.8 \pm 4.6$ \\
\hline $\begin{array}{l}\text { 4. Glucagon } \\
\text { GIP }\end{array}$ & $\begin{array}{l}0.5 \\
1.0\end{array}$ & $21.9 \pm 3.6$ \\
\hline $\begin{array}{l}\text { 5. Glucagon } \\
\text { Insulin } \\
\text { GIP }\end{array}$ & $\begin{array}{l}0.5 \\
0.1 \\
1.0\end{array}$ & $10.7 \pm 1.7^{*}$ \\
\hline
\end{tabular}

$*=p<0.01$ from 3 (Student's $t$-test)

Hormones were infused into the portal vein as indicated in Fig. 1. Glucose output was calculated as described in Fig.2. Values are means \pm SEM of 3, 6, 4, 4 experiments for data group $1,2,3,4,5$ respectively

crease of lactate uptake was observed (Fig.1A). Since hepatic lactate uptake increased much less (at the peak in $\mathrm{C}_{6}$ units $\sim 0.5 \mu \mathrm{mol} \cdot \mathrm{min}^{-1} \cdot \mathrm{g} \mathrm{liver}^{-1}$ ) than glucose output $\left(\sim 4 \mu \mathrm{mol} \cdot \mathrm{min}^{-1} \cdot \mathrm{g} \mathrm{liver}^{-1}\right)$, increased glucose production resulted predominantly from glycogenolysis. Upon cessation of hormone infusion, glucose output and lactate uptake returned to preinfusion values. The increase of glucose production by the liver following glucagon infusion was dose-dependent with a half maximal effective portal vein concentration of $\sim 30 \mathrm{pmol} / 1$ (Fig. 2A).

\section{Suppression of the glucagon-dependent stimulation of glycogenolysis by insulin}

Simultaneous infusion of insulin and glucagon $(0.5 \mathrm{nmol} / 1)$ resulted in a dose-dependent suppression of glucagon-stimulated glycogenolysis with a half maximal effective insulin concentration of about $2 \mathrm{nmol} / 1$ (Fig. 2B). At a portal vein concentration of $0.1 \mathrm{nmol} / 1$, insulin did not alter glucagon-stimulated glucose output (Fig. 1B).

\section{Effect of GIP on hepatic glucose output}

Infusion of GIP alone ( $1 \mathrm{nmol} / \mathrm{l}$ ) did not change hepatic glucose output appreciably compared to preinfusion values (Table 1). Simultaneous infusion of glucagon $(0.5 \mathrm{nmol} / 1)$ and GIP at high concentration $(1 \mathrm{nmol} / \mathrm{l})$ resulted in a slight reduction of glucose output (Table 1).

When GIP was infused simultaneously with insulin $(0.1 \mathrm{nmol} / 1)$ a dose-dependent inhibition of glucagonstimulated glucose production was observed (Fig.3). A maximum suppression of up to $70 \%$ was achieved (Fig. 1C). This could already be demonstrated at a physiological hormone concentration of $0.1 \mathrm{nmol} / 1$ (Fig. 3). 


\section{Discussion}

Regulation of hepatic carbohydrate metabolism is achieved by a variety of hormones, especially insulin and glucagon $[16,17]$, and by the autonomic nervous system $[12,18]$. Since it has been demonstrated that GIP as a component of the entero-insular axis modulates insulin secretion from the endocrine pancreas [1,2], an indirect insulin-mediated contribution to the regulation of hepatic glucose metabolism is well established. In contrast, direct metabolic effects of GIP on the liver have received little attention; moreover, results of in vitro and in vivo studies yielded contradictory data [8-10]. A consistent effect of insulin on hepatic carbohydrate metabolism in the perfused liver is its antagonistic action towards glucagon-stimulated glycogenolysis [19].

In the present study it was shown that GIP also exerts a direct inhibitory action on glucagon-stimulated glycogenolysis in the presence of insulin. The infusion of GIP alone into the portal vein did not change glucose balance (Table 1). This observation is at variance with data reported by Hanks et al. [8] which demonstrated an increase of glucose production following infusion of GIP $(\sim 1 \mathrm{nmol} / 1)$ in perfused livers from fasted rats. However, a more recent study by these authors also found that GIP alone does not alter hepatic glucose balance under normo- and hyperglycaemic conditions in perfused livers from fed as well as from fasted animals [20]. In the present study a non-recirculating medium with a high content of erythrocytes $(30 \% \mathrm{v} / \mathrm{v})$ has been used which allows physiological flow rates [13,14]. This experimental approach has been shown to reliably detect minor changes in metabolite balances across the liver [21].

Simultaneous infusion of glucagon and GIP resulted only in a slight reduction of glucagon-stimulated glycogenolysis at high GIP concentration. However, when insulin was present in the medium at a low concentration which by itself did not significantly affect glucose output, GIP suppressed glucagon-stimulated glycogenolysis in a dose-dependent way. These data are in accordance with earlier findings from our laboratory [9], and with in vivo studies reported recently by Andersen et al. who showed an insulin-dependent inhibition of glucagon-stimulated hepatic glucose production by GIP in conscious dogs [10]. The underlying molecular events at the hepatocytes have not been elucidated.

The physiological significance of this insulin-dependent but direct metabolic effect of GIP is not clear. However, it is of interest that not only pancreatic but also gut hormones directly participate in the regulation of hepatic carbohydrate metabolism. Taken together with the finding that GIP also directly stimulates triglyceride uptake [7], this gut peptide seems to act as an anabolic hormone.

Acknowledgements. The authors thank S. Zachmann for expert technical assistance and C. Stieler for help in preparing the manuscript.

\section{References}

1. Brown JC, Dryburgh JR, Ross SA, Dupré J (1975) Identification and actions of gastric inhibitory polypeptide. Rec Progr Horm Res $31: 487-532$

2. Pederson RA, Brown JC (1976) The insulinotropic action of gastric inhibitory polypeptide in the perfused isolated rat pancreas. Endocrinology 99: 780-785

3. Creutzfeldt W (1979) The incretin concept today. Diabetologia 16: $75-85$

4. Dupré J, Greenridge N, McDonald TJ, Ross SA, Rubenstein D (1976) Inhibition of actions of glucagon in adipocytes by gastric inhibitory polypeptide. Metabolism 25: 1197-1199

5. Ebert R, Brown JC (1976) Effect of gastric inhibitory polypeptide (GIP) on lipolysis and cyclic AMP levels in isolated fat cells. Eur J Clin Invest 6:327 (Abstract)

6. Eckel RH, Fujimoto WY, Brunzell JD (1979) Gastric inhibitory polypeptide enhanced lipoprotein lipase activity in cultured preadipocytes. Diabetes 28:1141-1142

7. Wasada T, McCorkle K, Harris V, Kawai K, Howard B, Unger RH (1981) Effect of gastric inhibitory polypeptide on plasma levels of chylomicron triglycerides in dogs. J Clin Invest 68: 1106-1107

8. Hanks JB, Meyers WC, Andersen DK, Hill RC, Jones RS (1979) The effects of gastric inhibitory polypeptide (GIP) on hepatic glucose production. Gastroenterology 76:1150 (Abstract)

9. Ebert R, Arends J, Creutzfeldt W (1983) Insulin-dependent suppression of hepatic glucose output by GIP in the perfused rat liver. Regul Pept 1 [Suppl 2]: 162 (Abstract)

10. Andersen DK, Sun YS, Brunicardi FC, Berlin SA, Lebovitz HE, Garksy V, Elahi D (1984) Regulation of hepatic glucose production by gastric inhibitory polypeptide (GIP), insulin (INS), and glucagon (GLUC). Dig Dis Sci 29 [August Suppl]: 6 S (Abstract)

11. Jungermann K, Heilbronn R, Katz N, Sasse D (1982) The glucose/glucose-6-phosphate cycle in the periportal and perivenous zone of rat liver. Eur J Biochem 123: 429-436

12. Hartmann H, Beckh K, Jungermann K (1982) Direct control of glycogen metabolism in the perfused rat liver by the sympathetic innervation. Eur J Biochem 123: 521-526

13. Dhumeaux D, Berthelot P (1973) Measurement of hepatic blood flow in the rat. Transhepatic catheterization of the hepatic veins. Biol Gastroenterol 6: 49-54

14. Ossenburg EW, Danis P, Benhamou JP (1974) Hepatic blood flow in the rat: effect of portocaval shunt. J Appl Physiol 37: 806-808

15. Bergmeyer HU (ed) (1974) Methoden der Enzymatischen Analysen, 3. Aufl, Bd 2. Verlag Chemie, Weinheim

16. Hue L, Van de Werve G (1981) (eds) Short-term regulation of liver metabolism. Elsevier/North Holland Biomedical Press, Amsterdam New York

17. Hems DA, Whitton PD (1980) Control of hepatic glycogenolysis. Physiol Rev 60: 1-50

18. Lautt WW (1983) Afferent and efferent neural roles in liver function. Progr Neurobiol 21:323-348

19. Mackrell DJ, Sokal JE (1969) Antagonism between the effects of insulin and glucagon in the isolated liver. Diabetes 18:724-732

20. Hanks JB, Andersen DK, Wise JE, Putnam WS, Meyers WC, Jones RS (1984) The hepatic extraction of gastric inhibitory polypeptide and insulin. Endocrinology 115: 1011-1018

21. Beckh K, Hartmann H, Jungermann K (1982) Modulation by insulin and glucagon of the activation of glycogenolysis by perivascular nerve stimulation in the perfused rat liver. FEBS Lett 146: $69-72$

Received: 7 June 1985

and in revised form: 25 November 1985

Prof. Dr. W.Creutzfeldt

Medizinische Universitätsklinik

Robert-Koch-Strasse 40

D-3400 Göttingen

FRG 